WARSZTATY Z GEOGRAFII TURYZMU

ISBN 978-83-7969-138-8 s. 9-18

http://dx.doi.org/10.18778/7969-138-8.02

Justyna LIRO

Uniwersytet Jagielloński

\title{
PRZEGLĄD BADAŃ NAD SANKTUARIAMI I RUCHEM PIELGRZYMKOWYM W KONTEKŚCIE PRZEMIAN STREF SAKRALNYCH
}

\section{Wstęp}

Ośrodki pielgrzymkowe stanowią istotny przedmiot badań w dziedzinie geografii, zwłaszcza geografii turyzmu i geografii religii. Sanktuaria Kościoła rzymskokatolickiego odwiedza $700 \mathrm{mln}$ osób rocznie na świecie (PARK 1994). W Polsce funkcjonuje ponad 500 sanktuariów (JACKOWSKI 1987). Według definicji prawnokanonicznej Kościoła rzymskokatolickiego, sanktuarium to kościół lub inne miejsce sakralne odwiedzane przez licznych pielgrzymów. Przedmiot kultu w danym sanktuarium jest podmiotem szczególnej pobożności wiernych (Dudziak 1983, za: SOŁJAN 2012). Z kolei koncepcja miejsc świętych wypracowana na gruncie nauk religioznawczych i antropologicznych (ELIADE 1959, STODDARD 1987, JORDAN i ROWNTREE 1990, LEEUW 1997, VUKONIC 2000) podkreśla świętość miejsca wynikająca z obecności szeroko pojętego sacrum oraz przywiązanie do niego osób wierzących.

W naukach geograficznych ujmuje się sanktuaria jako realne i funkcjonalne fragmenty przestrzeni geograficznej (JACKSON, HENRIE 1983, RINSCHEDE, SIEVERS 1987, SOŁJAN 2011, 2012). Według takiego ujęcia za przestrzeń sanktuarium/strefę sakralną przyjmuje się fragment realnej przestrzeni geograficznej o dominującej funkcji religijnej i zorganizowanej wokół 
głównego obiektu sakralnego (SOŁJAN 2012). Wyróżnia się trzy atrybuty tej przestrzeni: religijność miejsca, organizację przestrzenną i organizację społeczną (SOŁJAN 2012). Obok przestrzeni sanktuarium wyróżnia się dodatkowo tzw. strefę przysanktuaryjną obejmującą obszar poza strefą sakralną, o dużej aktywności pielgrzymów i przekształconą przez pełnioną funkcję (SOŁJAN 2012). Cały obszar tworzy integralną całość pod względem funkcjonalnym, której wyznacznikiem jest religijny charakter miejsca.

Celem pracy jest analiza polskiej i anglojęzycznej literatury dotyczącej tematyki sanktuariów i ruchu pielgrzymkowego. Ze względu na specyficzny charakter krajobrazu religijnego Polski przegląd literatury został zawężony do sanktuariów Kościoła rzymskokatolickiego. Szczególną uwagę zwrócono na prace pionierskie $\mathrm{z}$ uwagi na tematykę i stosowaną metodologię.

\section{Stan badań}

\subsection{Istotność problemu w studiach geograficznych}

W badaniach geograficznych podkreśla się istotny wpływ zjawisk religijnych na przestrzeń, zwłaszcza ośrodków pielgrzymkowych, i związany z nimi ruch pielgrzymkowy (KASCHE 1795, ZABORSKI I WRZOSEK 1939, ISAAC 1960, 1962, FICKELER 1947, TUAN 1978, SOPHER 1967, 1981, BUTNNER 1979, WIRTH 1979, HOHEISEL 1985, MARGUL 1986, RINSCHEDE, SIEVERS 1987, EADE, SALLNOW 1991, COHEN 1992, COOPER 1992, RINSCHEDE 1992, 1999, PARK 1994, JACKOWSKI, SOŁJAN, BILSKA-WODECKA 1999, HENKEL 2001, HOLLOWAY, VALLINS 2002, JACKOWSKI 2003). Często stosowane w geografii religii są także prace z zakresu socjologii antropologii kulturowej (TURNER 1973, 1979, EADE, SALLNOW 1991, STODDARD, MORINIS 1997). Rolą geografii religii według niektórych autorów powinno być właściwe odczytywanie i interpretacja najważniejszych przejawów kultu w przestrzeni geograficznej (FICKELER 1947). P. DEFFONTAINES (1948) podkreślił rolę i funkcję osadniczą ośrodków kultowych, jak również znaczenie pielgrzymek dla rozwoju miejscowości o funkcji religijnej. Już na początku II poł. XX w. w wybranych badaniach zaczęto zwracać uwagę na religijną organizację przestrzeni geograficznej (SOPHER 1967). W kluczowych pracach wyznaczających nowe kierunki geografii religii podkreśla się znaczenie badań nad sanktuariami i ruchem pielgrzymkowym oraz ich wpływem na przestrzeń geograficzną (RINSCHEDE, SIEVERS 1987, PARK 1994, RINSCHEDE 1999, JACKOWSKI 2003). 


\subsection{Sanktuaria jako przedmiot badań $w$ geografii religii}

Wśród dotychczasowych badań nad ośrodkami sanktuaryjnymi można wyróżnić cztery główne nurty:

- badania syntezujące dotyczące m.in. genezy i występowania miejsc świętych;

- badania zjawiska pielgrzymowania, obejmujące m.in. wpływ pielgrzymek na powstanie i rozwój miejscowości;

- badania struktury i wielkości ruchu pielgrzymkowego oraz zasięgu oddziaływania ośrodków pielgrzymkowych;

- prace o charakterze opisowym, monograficznym, studia przypadku wybranego sanktuarium.

W naukach geograficznych w kontekście sanktuariów najwięcej badań podejmowano nad ruchem pielgrzymkowym (JACKOWSKI 1987, 1990, RINSCHEDE, SIEVERS 1987, JACKOWSKI, SMITH 1992, JACKOWSKI, SOŁJAN, BILSKA-WODECKA 1999, COLLINS-KREINER 2010a, 2010b, 2010c). Dużą grupę opracowań stanowią prace monograficzne opisujące przede wszystkim wielkość i strukturę ruchu pielgrzymkowego oraz zawierające informacje na temat rozwoju i funkcjonowania sanktuariów (tab. 1).

Tabela 1. Publikacje monograficzne na temat sanktuariów

\begin{tabular}{|l|l|}
\hline \multicolumn{1}{|c|}{ Obszar badań } & \multicolumn{1}{c|}{$\begin{array}{c}\text { Nazwisko autora } \\
\text { i rok wydania }\end{array}$} \\
\hline $\begin{array}{l}\text { Świat } \\
\text { - opracowanie ogólne }\end{array}$ & ARADI 1954, STODDARD 1994, JACKOWSKI 2003, MANGRY 2008 \\
\hline Stany Zjednoczone & RINCHEDE 1990 \\
\hline Europa & CARTWRIGHT 1955, SOEJAN 2012 \\
\hline Europa Zachodnia & NOLAN 1987a, 1987b, NOLAN i NOLAN 1989, 1992 \\
\hline Wielka Brytania & HOLE 1954, GILLET 1957, DOWSE 1963, SHACKLEY 2002 \\
\hline Polska & JACKOWSKI 1987, 1990, CIECHOCIŃSKA 1989, MRÓZ 2000, 2008, \\
& HODOROWICZ i MRÓZ 2009, SOŁJAN 2002, 2011 \\
\hline
\end{tabular}

Źródło: opracowanie własne.

Warte uwagi są prace o kompleksowym charakterze, opisujące historyczne uwarunkowania rozwoju sieci sanktuariów w Europie Zachodniej w przekrojach czasowych (NOLAN 1987a,b, NOLAN, NOLAN 1989). Liczne studia przypadku zawierają głównie informacje na temat historii i wielkości ruchu pielgrzymkowego ośrodka kultu (tab. 2). 
Tabela 2. Publikacje - studia przypadków dotyczące sanktuariów

\begin{tabular}{|c|c|c|}
\hline Nazwa sanktuarium & Miejscowość & $\begin{array}{l}\text { Nazwisko autora } \\
\text { i rok wydania }\end{array}$ \\
\hline Matki Bożej Królowej Bawarii & Altotting & HOELDL 1962 \\
\hline $\begin{array}{l}\text { Matki Bożej Niepokalanego } \\
\text { Poczęcia }\end{array}$ & Fatima & RINSCHEDE 1988, SOŁJAN 2012 \\
\hline Matki Bożej Gietrzwałdzkiej & Gietrzwałd & JACKOWSKI I SOŁJAN 2003 \\
\hline Matki Bożej Częstochowskiej & Jasna Góra & $\begin{array}{l}\text { GROCH 1996, JACKOWSKI 1996, JACKOWSKI, PTA- } \\
\text { SZYCKA-JACKOWSKA 1998, SOŁJAN 2011, } 2012\end{array}$ \\
\hline Pasyjno-maryjne & $\begin{array}{l}\text { Kalwaria Zeb- } \\
\text { rzydowska }\end{array}$ & JACKOWSKI 1995 \\
\hline $\begin{array}{l}\text { Matki Bożej Pocieszycielki } \\
\text { Strapionych }\end{array}$ & Kevelaer & $\begin{array}{l}\text { OOMEN 1976, BOYMANN i BOYMANN 1979, } \\
\text { BILSKA-WODECKA, SOEJAN } 2005\end{array}$ \\
\hline Miłosierdzia Bożego & Kraków & $\begin{array}{l}\text { JANIEC 1995, JACKOWSKI i SOEJAN 2000, 2001, } \\
\text { JACKOWSKI 2011, LIRO } 2014\end{array}$ \\
\hline Bł. Jana Pawła II & Kraków & $\operatorname{LIRO}(\mathrm{w}$ druku) \\
\hline Wybrane sanktuaria & Kraków & KASZOWSKI 2003, GÓRKA 2004 \\
\hline Matki Bożej Pocieszenia & Leżajsk & JACKOWSKI 1999 \\
\hline Santa Casa & Loreto & RINSCHEDE 1995 \\
\hline Matki Bożej z Lourdes & Lourdes & $\begin{array}{l}\text { LASSERE 1930, MARNHAM 1980 \& RINSCHEDE } \\
\text { 1985, EADE 1992, PIHET, VIOLER 1993, BRANT- } \\
\text { HOMME, TOUVET 2005, SOEJAN 2005, 2009, } 2012\end{array}$ \\
\hline Matki Bożej Pocieszenia & Pasierbiec & KAPERA 2005 \\
\hline Cudownego Medalika & Paryż & ZACHWIEJA 2005 \\
\hline Matki Bożej Uśmiechniętej & Pszów & DRAŻYK 2000 \\
\hline Św. Ojca Pio & $\begin{array}{l}\text { San Giovanni } \\
\text { Rotondo }\end{array}$ & MCKEVITT 1991, SOŁJAN 2012 \\
\hline Królowej Kaszub & Sianowo & BELGRAU 2001 \\
\hline Wybrane sanktuaria & Quebec & RINSCHEDE 1994 \\
\hline Matki Bożej Zielenickiej & Zielenice & SWARYSZEWSKA 1996 \\
\hline
\end{tabular}

Źródło: opracowanie własne.

W studiach teoretyczno-metodologicznych nad sanktuariami część autorów podjęła również próbę sporządzenia modeli lokalizacji sanktuariów (SOPHER 1981, EADE, SALLNOW 1991, SOŁJAN 2011), w których wykazano, iż uwarunkowania historyczne mają wpływ na lokalizację i rozwój wybranych ośrodków w Europie. W przedstawionych powyżej pracach brak jest wyjścia poza badania wielkości i struktury ruchu pielgrzymkowego oraz informacji ogólnych nt. rozwoju i funkcjonowania danego sanktuarium. 


\section{Pionierskie badania nad strukturą funkcjonalną i przestrzenną sanktuariów}

W ostatnich latach pojawiają się prace dotyczące tematyki sanktuariów i ruchu pielgrzymkowego, wychodzące poza charakter opisowy. Prace te ze względu na nową metodologię i metody badań, obejmujące m.in. analizę dynamiczno-porównawczą, można uznać za pionierskie i wyznaczające nowe kierunki badań nad ośrodkami sanktuaryjnymi. $W$ tab. 3 przedstawiono prace zawierające badania struktury funkcjonalnej i przestrzennej sanktuariów oraz nawiązujące tematycznie do przemian stref sakralnych w największych europejskich ośrodkach pielgrzymkowych.

Tabela 3. Opublikowane pionierskie badania nad strukturą funkcjonalną i przestrzenną sanktuariów

\begin{tabular}{|l|l|}
\hline \multicolumn{1}{|c|}{$\begin{array}{c}\text { Nazwisko autora } \\
\text { i rok wydania }\end{array}$} & \multicolumn{1}{c|}{ Sanktuarium } \\
\hline RINSCHEDE 1985 & Lourdes \\
\hline RINSCHEDE 1988 & Fatima \\
\hline RINSCHEDE 1995 & Loreto \\
\hline SOEJAN 2009 & Lourdes \\
\hline JACKOWSKI, SOŁJAN 2010 & Miłosierdzia Bożego w Krakowie-Łagiewnikach \\
\hline SOŁJAN 2012 & Największe sanktuaria europejskie \\
\hline
\end{tabular}

Źródło: opracowanie własne.

Wpływ na organizację przestrzeni sanktuariów mają zarówno uwarunkowania historyczne, społeczne, jak również ranga danego sanktuarium i zasięg ruchu pielgrzymkowego (RINSCHEDE 1985, 1988, 1995, SOŁJAN 2011, SOŁJAN 2012). Lokalizacja sanktuarium i jego rozwój mogą powodować daleko idące zmiany w strukturze przestrzenno-funkcjonalnej otoczenia (JACKOWSKI, SOŁJAN 2010, SOŁJAN 2012). Największe przemiany obserwowane są $\mathrm{w}$ najbliższym otoczeniu obiektu sakralnego, tj. w strefie sakralnej (SOŁJAN 2012). W sanktuariach powstałych przed XIX w. powszechna jest strefa sakralna prosta (SOŁJAN 2012). Centrum przestrzeni sanktuarium stanowi jedynie główny obiekt sakralny (tzw. rdzeń). Współcześnie strefa sakralna może być bardzo złożona. Składają się na nią obiekty sakralne, inne obiekty o charakterze religijnym oraz obiekty służące zaspokajaniu pozareligijnych potrzeb pielgrzymów (SOŁJAN 2012). Obecnie obserwowana jest coraz bardziej zróżnicowana struktura przestrzenna ośrodków sanktuaryjnych. Rozwój 
złożonej strefy sakralnej można zaobserwować w największych europejskich ośrodkach sanktuaryjnych, tj. Lourdes, Fatima, San Giovanni Rotondo, Kraków-Łagiewniki. Współczesne sanktuaria, stanowiące pod względem przestrzennym i funkcjonalnym kompleksy religijne, powstały w większości od II poł. XIX w. do czasów obecnych (SOŁJAN 2012). Rozbudowa przestrzeni sanktuarium i poszerzenie oferty pełnionych usług, również pozareligijnych, jest odpowiedzią na zapotrzebowanie turystów i pielgrzymów.

G. Rinschede w pracach studialnych podejmował badania nad rozwojem przestrzennym sanktuariów i ich wpływem na rozwój miejscowości, infrastruktury oraz bazy turystycznej w ośrodkach pielgrzymkowych w Europie (1985, 1988, 1995). I. SOŁJAN (2012) przedstawia sanktuarium jako realny i funkcjonalny fragment przestrzeni geograficznej wpływający na organizację przestrzenni miejskiej. Organizacja przestrzenna sanktuarium wynika z pełnionych przez nie funkcji, stanowiąc określoną przestrzeń społeczną i publiczną (SOŁJAN 2012). Analogicznie, jak w przypadku przestrzeni turystycznej, której głównym elementem jest ruch turystyczny, zasadniczą cechą przestrzeni sanktuarium jest zachodzący na jej obszarze ruch pielgrzymkowy.

\section{Wnioski}

Większość prac na temat sanktuariów obejmuje głównie badania wielkości i struktury ruchu pielgrzymkowego. Dużą grupę opracowań stanowią opisowe prace monograficzne i studia przypadków wybranych ośrodków sanktuaryjnych. W opracowaniach tych zawarte są informacje nt. m.in. rozwoju, historii i rangi danego sanktuarium. W studiach geograficznych podkreśla się konieczność podjęcia badań nad genezą i funkcjonowaniem sanktuariów w przestrzeni i ich rozwojem (FICKELER 1947, DEFFONTAINES 1948, ISSAC 1960, SOPHER 1981, RINSCHEDE, SIEVERS 1987, EADE, SALLNOW 1991, PARK 1994, STODDARD 1994, RINSCHEDE 1999, JACKOWSKI 2003, SOŁJAN 2012). Istotne są prace, otwierające drogę do nowych badań nad przemianami stref sakralnych w ujęciu czasowo-przestrzennym (RINSCHEDE 1985, 1988, JACKOWSKI, SOŁJAN 2010, SOŁJAN 2012), w których nawiązano do rozwoju i przemian stref sakralnych w największych europejskich ośrodkach pielgrzymkowych. Terminologia i metodologia wypracowana przez G. RINSCHEDE $(1985,1988$, 1995) i I. SOŁJAN (2012), ujmująca sanktuarium jako realny i funkcjonalny 
fragment przestrzeni geograficznej zdominowany przez funkcję religijną, umożliwia prowadzenie nowych badań nad przemianami stref sakralnych ośrodków sanktuaryjnych.

\section{LITERATURA}

ARADI Z., 1954, Shrines of Our Lady around the World, Nowy Jork, Farrar Straus and Toung.

Belgrau J., 2001, Sianowo Sanktuarium Królowej Kaszub, „Peregrinus Cracoviensis”, 12, s. 210224.

BilsKa-WodeCKA E., SOŁJAN I., 2005, Sanktuarium Matki Bożej Pocieszycielki Strapionych w Kevelaer. Katolicka „oaza” w protestanckiej Westfalii Pótnocnej, „Peregrinus Cracoviensis”, 16, s. 139-148.

BOymann G.G., Boymann O., 1979, The basilica in Kevelaer, Verlag Schnell \& Steiner, Zurich.

BRANTHOMme H., TOUVET C., 2005, Historie des sanctuaries de Lourdes, 1947-1988, NDL Editions, Lourdes.

BUTNNER M., 1979, Religion and Geography: impulses for a new dialogue between religionwissenschaffen and geography, "Numen”, no. 21, s. 163-169.

CARTWRIGHT J.K., 1955, The catholic shrines of Europe, McGraw-Hall, New York.

CiECHOCIŃSKA M., 1989, Geography of the Roman Catholic Church in Poland, "National Geographical Journal of India", 35, s. 115-128.

COHEN E., 1992, Pilgrimage centers: Concentric and excentric, "Annals of Tourism Research", 19, s. 33-50.

Collins-Kreiner N., 2010a, Geographers and Pilgrimages: Changing Concepts in Pilgrimage Tourism Research, "Tijdschrift voor economische en sociale geografie", 101 (4), s. 437-448.

COLLINS-KREINER N., 2010b, Researching pilgrimage, "Annals of Tourism Research”, 37 (2), s. $440-456$.

COLLINS-KREINER N., 2010c, The geography of pilgrimage and tourism: Transformations and implications for applied geography, "Applied Geography", 30 (1), s. 153-164.

COOPER A., 1992, New directions in the geography of religion, "Area”, 24, s. 123-129.

DeFFONTAINES P., 1948, Geographie et religions, "Geographie Humaine”, 21, Gallimard, Paris.

DOWSE I., 1963, The pilgrim shrines of England, The Faith Press, London.

DRAŻYK M., 2000, Sanktuarium Matki Bożej Uśmiechniętej w Pszowie, „Peregrinus Cracoviensis”, 8, s. 165-182.

DudZIAK J., 1983, Prawno-kanoniczna koncepcja sanktuarium, „Tarnowskie Studia Teologiczne”, 9, s. $60-73$.

EADE J., 1992, Pilgrimage and tourism at Lourdes, France, "Annals of Tourism Research", 19, s. $18-32$.

EAdE J., SAlLnOW M.J., 1991, Contesting the sacred. The anthropology of Christian pilgrimage, University of Illinois Press, London-New York.

ELIADE M., 1959, The sacred and the profane the nature of religion, Harcourt, Brace \& World, New York.

FICKELER P., 1947, Fundamental questions in the geography of religion, [w:] P.L. Wegner, M.W. Mikesell (eds), Reading in Cultural Geography, Chicago, s. 23-28.

GILLET H.M., 1957, Famous shrines of Our Lady England and Wales, Samuel Walker, London. 
GóRKA Z., 2004, Krakowska dzielnica staromiejska w dobie społeczno-ekonomicznych przemian Polski na przełomie XX i XXI wieku, IGiGP UJ, Kraków.

GROCH J., 1996, Miastotwórcza funkcja sanktuarium jasnogórskiego, „Peregrinus Cracoviensis”, 3, s. 205-218.

HENKEL R., 2001, Geography of Religion, [w:] Encyclopedia of Christianity, 2, Michigan.

HodOROWICZ I., MRÓz F., 2009, Sanktuaria świętych i błogosławionych w Karpatach polskich, [w:] A. Jackowski, I. Hodorowicz, F. Mróz (red.), Turystyka religijna na obszarach górskich, Państwowa Wyższa Szkoła Zawodowa, Nowy Targ, s. 153-172.

HoELDL F.X., 1962, Altotting, Drittordebsverlag, Altotting.

HOHEISEL K., 1985, Geografia religii, [w:] H. Waldenfels (red.), Leksykon religii, Warszawa.

HOLE C., 1954, English shrines and sanctuaries, Batsford, London.

HollowAy J., VALLINS O., 2002, Placing religion and spirituality in geography, „Social and Cultural Geography", 3, s. 5-9.

IsAAC E., 1960, Religion, landscape and space, "Landscape”, 9, s. 14-18.

ISAAC E., 1962, The act and the covenant: the impact of religion on the landscape, "Landscape, 11, s. 12-17.

JACKOWSKI A., 1987, Geography of pilgrimage in Poland, „National Geographical Journal of India”, 33, s. 422-429.

JACKOWSKI A., 1990, Development of pilgrimages in Poland: Geographical - historical study, [w:] G. Lallanji, D.P. Dubey (eds), Pilgrimage Studies: Text and Context, s. 241-50, Allahabad.

JACKOWSKI A., 1995, Tradycje, wspótczesność i przyszłość pielgrzymek w Kalwarii Zebrzydowskiej, „Peregrinus Cracoviensis", 2.

JACKOWSKI A., 1996, Jasna Góra the World Centre of Pilgrimage , "Peregrinus Cracoviensis”, 3.

JACKOWSKI A., 1999, Czterysta lat Sanktuarium Matki Bożej Pocieszenia w Leżajsku, „Peregrinus Cracoviensis", 7.

JACKOWSKI A., 2003, Święta przestrzeń świata. Podstawy geografii religii, Wyd. Uniwersytetu Jagiellońskiego, Kraków.

JACKOWSKI A., 2011, Eagiewniki in the system of Poland's and World's Pilgrimage Centres, "Peregrinus Cracoviensis", 22, s. 143-152.

JACKOWSKI A., PTASZYCKA-JACKOWSKA D., 1998, Jasnogórskie pielgrzymki w przestrzeni miasta i regionu Częstochowy, IGiGP UJ, Kraków.

JACKOWSKI A., SMITH V.S., 1992, Polish pilgrim-tourists, „Annals of Tourism Research”, 19, s. 92-106.

JACKOWSKI A., SOŁJAN I., 2000, Nowy klejnot w koronie Krakowa, „Peregrinus Cracoviensis”, 9.

JACKOWSKI A., SOŁJAN I., 2001, New Jewel in the Crown of Cracow, „Peregrinus Cracoviensis”, 11.

JACKOWSKI A., SOŁJAN I., 2003, Gietrzwałd w systemie ośrodków pielgrzymkowych Europy i Polski, Maryjne Orędzie z Gietrzwałdu, Częstochowa-Gietrzwałd, s. 79-90.

JACKOWSKI A., SOŁJAN I., 2010, Rozwój Sanktuarium Miłosierdzia Bożego w Krakowie-Łagiewnikach i jego wptyw na przemiany przestrzenno-funkcjonalne dzielnicy Eagiewniki i Borek-Fałecki, [w:] S. Ciok, P. Migoń (red.), Przekształcenia struktur regionalnych. Aspekty społeczne, ekonomiczne i przyrodnicze, Wyd. Uniwersytetu Wrocławskiego, Wrocław.

JACKOWSKI A., SOŁJAN I., BILSKA-WODECKA E., 1999, Religie świata. Szlaki pielgrzymkowe, Wyd. Kurpisz, Poznań.

JACKSON R.H., HENRIE R., 1983, Perception of sacred space, „Journal of Cultural Geography", no. 3, s. 94-107. 
JANIEC R., 1995, Sanktuarium Bożego Miłosierdzia w Eagiewnikach jako obiekt kultu religijnego, „Peregrinus Cracoviensis", 1, s. 147-152.

Jordan T.G., RownTREE L., 1990, The Human Mosaic: a Thematic Introduction to Cultural Geography, Harper and Row, New York.

KAPERA I., 2005, Sanktuarium Matki Bożej Pocieszenia w Pasierbcu, „Peregrinus Cracoviensis”, 16, s. $183-192$.

KASCHE G. H., 1795, Ideas about religious geography, Lubeck.

KASZOWSKI L., 2003, Skałka -- Sanktuarium i Panteon Narodu. 750-lecie kanonizacji św. Stanisława Biskupa i Męczennika, „Peregrinus Cracoviensis”, 14.

LASSERE P., 1930, Lourdes etude geographique, „Revue Geographique des Pyresees et du Sud-Quest", 1, s. 1-36.

LEEUW G., 1997, Fenomenologia religii, KiW, Warszawa.

LIRO J., 2014, Znaczenie Sanktuarium Miłosierdzia Bożego i Centrum Jana Pawła II "Nie lękajcie się" w ksztattowaniu funkcji pielgrzymkowej Krakowa, [w:] R. Pawlusiński (red.), Wspótczesne uwarunkowania rozwoju turystyki, IGiGP UJ, Kraków, s. 385-392.

LIRO J., w druku, Sanktuarium bt. Jana Pawła II w Krakowie jako obiekt kultu religijnego, „Peregrinus Cracoviensis", 24.

MANGRY J.P., 2008, Shrines and pilgrimage in the modern world: New itineraries into the sacred, University of Amsterdam Press, Amsterdam.

MARGUL T., 1986, Religia a przestrzeń i krajobraz, Wyd. Uniwersytetu Jagiellońskiego, Kraków.

MARNHAM P., 1980, Lourdes a modern pilgrimage, Coward Maccann and Geoghegan, New York.

McKevitT C., 1991, San Giovanni Rotondo and the shrine of Padre Pio, [w:] J. Eade, M. Sallnow (eds), Contesting the Sacred: The Anthropology of Christian Pilgrimage, Routledge, London, s. 77-97.

MrÓz F., 2000, Sanktuaria i kaplice Bożego Grobu w Polsce, „Peregrinus Cracoviensis”, 8, s. 79-114.

MrÓz F., 2008, Geneza i funkcjonowanie sanktuariów Bożego Miłosierdzia w Polsce, „Peregrinus Cracoviensis", 19, s. 47-72.

NOlan M. L., NOLAN S., 1992, Religious sites as tourism attractions in Europe, "Annals of Tourism Research", 19, s. 69-79.

NolAN M.L., 1987a, A profile of Christian pilgrimage shrines in Western Europe, "Journal of Cultural Geography", 7, s. 5-20.

NolAN M.L., 1987b, Christian pilgrimage shrines in Western Europe and India; a preliminary comparison, „National Geographical Journal of India”, 33, s. 370-378.

Nolan M.L., NOLAN S., 1989, Christian pilgrimage in modern Western Europe, University of North Carolina Press, London.

OOMEN J., 1976, Kevelar: origin and history of pilgrimage and sanctuaries, Wallfahrtseitung Priesterhaus, Kevelear.

PARK C.C., 1994, Sacred Worlds: An Introduction to Geography and Religion, Routledge, London.

Pinet C., Violer P., 1993, Lourdes. Przestrzeń miejska i funkcja turystyczna, "Turyzm”, 3, 2, s. 35-43.

RINSCHEDE G., 1985, The Pilgrimage Town of Lourdes, ",Journal of Cultural Geography", 7, s. 21-33.

Rinschede G., 1988, The Pilgrimage Center of Fatima/Portugal, "Geographia Religionum", 4, s. 65-98.

RINSCHEDE G., 1990, Catholic pilgrimage places in the United States, [w:] G. Rinschede, S.M. Bhardwaj (eds), Pilgrimage in the United States, Dietrich Reimer Verlag, Berlin.

RINSCHEDE G., 1992, Forms of religious tourism, „Annals of Tourism Research”, 19, s. 51-67. 
RINSCHEDE G., 1994, Catholic pilgrimage centers in Quebec, Canada, „National Geographical Journal of India", 40, s. 287-305.

RINSCHEDE G., 1995, The pilgrimage center of Loreto, Italy, „Pilgrimage Studies: Text and Context", 3, s. 157-178.

RINSCHEDE G., 1999, Religionsgeographie, Westermann Schulbuchverlag, Braunschweig.

RINSCHEDE G., SIEVERS A., 1987, The pilgrimage phenomenom in sociogeographical research, "The National Geographical Journal of India", 33, 3, s. 213-217.

SHACKLEY M., 2002, Space, sancity and service, the English Cathedral as heterotopia, "International Journal of Tourism Research" 4(5), s. 345-352.

SOŁJAN I., 2002, Funkcjonowanie sanktuariów maryjnych w Karpatach Polskich w latach 1772-1992, IGiGP UJ, Kraków, ss. 180.

SoŁJAN I., 2005, Fenomen Lourdes, [w:] B. Domański, S. Skiba (red.) Geografia i sacrum, t. 2, IGiGP UJ, Kraków, s. 431-439.

SOŁJAN I., 2009, Kształtowanie się strefy sacrum w Lourdes, [w:] B. Domański, W. Kurek (red.), Gospodarka i przestrzeń, IGiGP UJ, Kraków, s. 295-303.

SOEJAN I., 2011, The sanctuary as a means of organizing urban space: a case study of selected sanctuaries in Poland, "Tourism/Turyzm", 21, 1-2, s. 49-57.

SOŁJAN I., 2012, Sanktuaria $i$ ich rola $w$ organizacji przestrzeni miast na przykładzie największych europejskich ośrodków katolickich, IGiGP UJ, Kraków.

SOPHER D.E., 1967, Geography of religions, Prentice-Hall, Englewood Cliffs, New York.

SOPHER D.E., 1981, Geography and religion, „Progress in Human Geography”, 5, s. 510-524.

STODDARD R.H., 1987, Pilgrimages along sacred paths, „National Geographical Journal of India”, 33, s. 448-456.

STODDARD R.H., 1994, Major pilgrimage places of the world, "Geographia Religionum”, 8, s. 17-36.

StOdDARD R.H., MorinIS A.E., 1997, Sacred Places, Sacred Spaces: The Geography of Pilgrimages, Geoscience Publications, Baton Routlege.

SWARYSZEWSKA M., 1996, Sanktuarium maryjne XX. Orionistow w Zielinicach, „Peregrinus Cracoviensis", 5, s. 175-178.

TUAN Y.F., 1978, Sacred space: exploration of an idea, [w:] K.W. Butzer (ed.), Dimensions of Human Geography, University of Chicago Department of Geography, 186, s. 84-99.

Turner V., 1973, The Centre Out There: Pilgrim's Goal, „History of Religions”, 12, s. 191-230.

TURNER V., 1979, Process, performance and pilgrimage a study in comparative symbology, Ranchi Anthropology Series, Delhi.

VUKONIC B., 2000, Shrine. Encyclopedia of tourism, Taylor \& Francis Group, London.

WiRTH E., 1979, Theoretische Geographie, Stuttgart.

ZABORSKI B., WRZOSEK A., 1939, Antropogeografia, Warszawa.

ZACHWIEjA M., 2005, Sanktuarium Cudownego Medalika w Paryżu jako ośrodek kultu maryjnego, „Peregrinus Cracoviensis”, 16, s. 129-138. 